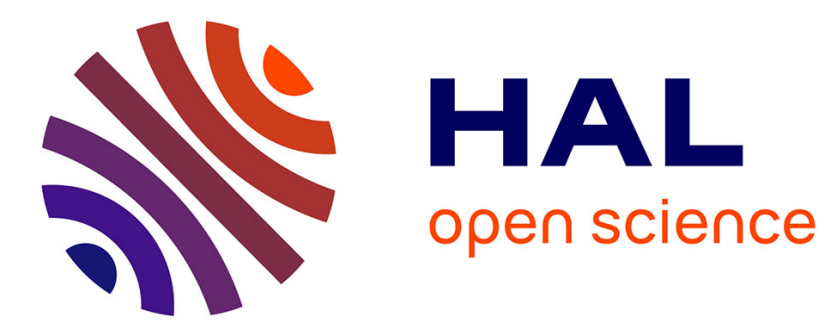

\title{
How many hydrogen-bonded $\alpha$-turns are possible?
}

\author{
Anette Schreiber, Peter Schramm, Hans-Jörg Hofmann
}

\section{To cite this version:}

Anette Schreiber, Peter Schramm, Hans-Jörg Hofmann. How many hydrogen-bonded $\alpha$-turns are possible?. Journal of Molecular Modeling, 2010, 17 (6), pp.1393-1400. 10.1007/s00894-010-0830-5 . hal-00623790

\section{HAL Id: hal-00623790 \\ https://hal.science/hal-00623790}

Submitted on 15 Sep 2011

HAL is a multi-disciplinary open access archive for the deposit and dissemination of scientific research documents, whether they are published or not. The documents may come from teaching and research institutions in France or abroad, or from public or private research centers.
L'archive ouverte pluridisciplinaire HAL, est destinée au dépôt et à la diffusion de documents scientifiques de niveau recherche, publiés ou non, émanant des établissements d'enseignement et de recherche français ou étrangers, des laboratoires publics ou privés. 


\title{
How many hydrogen-bonded $\alpha$-turns are possible?
}

Received: 27.05.2010 / Accepted: 22.08.2010

Anette Schreiber, Peter Schramm, and Hans-Jörg Hofmann ${ }^{\bowtie}$

Institute of Biochemistry, Faculty of Biosciences, Pharmacy, and Psychology, University of Leipzig, D-04103 Leipzig, Germany

${ }^{\square}$ Email: hofmann@uni-leipzig.de

\begin{abstract}
The formation of $\alpha$-turns is a possibility to reverse the direction of peptide sequences via five amino acids. In this paper, a systematic conformational analysis was performed to find the possible isolated $\alpha$-turns with a hydrogen bond between the first and fifth amino acid employing the methods of ab initio MO theory in vacuum (HF/6-31G*, B3LYP/6-311+G*) and in solution $\left(\mathrm{CPCM} / \mathrm{HF} / 6-31 \mathrm{G}^{*}\right)$. Only few $\alpha$-turn structures with glycine and alanine backbones fulfill the geometry criteria for the $i \leftarrow(i+4)$ hydrogen bond satisfactorily. The most stable representatives agree with structures found in the Protein Data Bank. There is a general tendency to form additional hydrogen bonds for smaller pseudocycles corresponding to $\beta$ - and $\gamma$-turns with better hydrogen bond geometries. Sometimes, this competition weakens or even destroys the $\mathrm{i} \leftarrow(\mathrm{i}+4)$ hydrogen bond leading to very stable double $\beta$-turn structures. This is also the reason why an "ideal" $\alpha$-turn with three central amino acids having the perfect backbone angle values of an $\alpha$-helix could not be localized. There are numerous hints for stable $\alpha$-turns with a distance between the $\mathrm{C}_{\alpha}$-atoms of the first and fifth amino acid smaller than 6-7 $\AA$, but without an $\mathrm{i} \leftarrow(\mathrm{i}+4)$ hydrogen bond.
\end{abstract}

Keywords Secondary structure $\cdot \alpha$-Turns $\cdot$ Conformational analysis $\cdot$ Ab initio MO theory - Protein design 


\section{Introduction}

Reverse turns and loops, which allow the reversal of the direction of peptide sequences, are important secondary structure elements for the formation of globular protein structures [1-10]. In the simplest way, chain reversal could formally be organized via two amino acids connected by a cis-peptide bond. However, such an arrangement brings the arriving and leaving strands, which are often $\alpha$-helices or $\beta$-strands, in too close contact. Turns via three amino acids, which are connected by trans-peptide bonds, are more realistic. Such $\gamma$-turns have a stabilizing intramolecular hydrogen bond between the $\mathrm{CO}$ group of the first and the $\mathrm{NH}$ group of the third amino acid. They occur in proteins and in linear and cyclic peptides [1, $3,4,10]$, but are still relatively rare because of sterical reasons. Much more frequent are $\beta$-turns realized via four amino acids. They are well examined and classified into various families [11-22]. The most important types of $\beta$-turns, the $\beta$ I- and $\beta$ II-turns and their approximate backbone mirror images $\beta \mathrm{I}^{\prime}$ and $\beta \mathrm{II}^{\prime}$, are characterized by hydrogen bonds between the $\mathrm{CO}$ group of the first and the $\mathrm{NH}$ group of the fourth amino acid. In comparison to $\beta$-turns, the so-called $\alpha$-turns over five consecutive amino acids with a hydrogen bond between the first and fifth amino acid are not so frequent. Therefore, they attracted less attention, although this hydrogen bond pattern corresponds to one turn of the famous $\alpha$-helix. A systematic search for hydrogen-bonded $\alpha$-turns, which are not part of an $\alpha$-helix, in 193 not structurally related proteins in the Protein Data Bank (PDB) by Pavone et al. [23] provided 349 isolated trans-configured $\alpha$-turns, which could be clustered into four types with their approximate backbone mirror images. These structures were essentially confirmed in a more extended analysis of the Protein Data Bank by Dasgupta et al. [24], who considered also structures without the $\mathrm{i} \leftarrow(\mathrm{i}+4)$ hydrogen bond, but with distances smaller than $7 \AA$ between the $\mathrm{C}_{\alpha}$ atoms of the amino acids $\mathrm{i}$ and $(\mathrm{i}+4)$ in a peptide sequence as potential $\alpha$-turn structures. Such a criterion is also valid for the distance between the $\mathrm{C}_{\alpha}$ atoms of the amino acids $i$ and (i+3) in $\beta$-turns $[13,15,16,20]$.

In a systematic conformational search on a blocked $\alpha$-turn model on the basis of molecular mechanics employing a force field suggested by Ramachandran and Sasisekharan [25], Ramakrishnan and coworkers [26, 27] looked for all possible hydrogen-bonded $\alpha$-turns. They found 23 minimum energy conformations, which they assigned to 13 different families of hydrogen-bonded $\alpha$-turns. Our detailed inspection of the geometry and the assignment of 
these $\alpha$-turns on the basis of quantum chemical calculations showed some inconsistencies, probably caused by the shortcomings of the empirical force field. This made us to revisit this conformational problem on the basis of the more sophisticated methods of ab initio MO theory.

\section{Computational details}

The blocked tripeptide $\mathbf{1}$ was chosen as a model compound for an $\alpha$-turn. The backbone angles $\varphi$ and $\psi$ of all amino acids were systematically varied in intervals of $30^{\circ}$ resulting in $12^{6}=2,985,984$ conformations.

\section{$<$ Structure formula 1 $>$}

These conformations were checked for the existence of a hydrogen bond between the first and fifth amino acids (distance criterion CO $\cdots \mathrm{HN}$ : 1.8-2.5 $\AA$ ). The energy of all conformations fulfilling the hydrogen bond criteria were calculated employing the CHARMM c32b1 force field [28] keeping the backbone torsion angles fixed. All structures within an energy range of $100 \mathrm{kcal} \mathrm{mol}^{-1}$ referred to the most stable one were selected for further studies. This analysis provided 2418 candidate structures for $\alpha$-turns. Since amino acid side chains are missing in the model peptide 1, only 1209 conformations had to be considered in the full geometry optimizations at the $\mathrm{HF} / 6-31 \mathrm{G}^{*}$ level of $a b$ initio $\mathrm{MO}$ employing the program package Gaussian 03 [29] (keyword: opt) to find all minimum conformations. The Gaussian 03 program package was also used for all other quantum chemical calculations. All optimized structures were checked for maintenance of the $\alpha$-turn hydrogen bond and for their minimum character by calculation of the vibration frequencies (keyword: freq). Changing the sign of the backbone torsion angles of all conformers leads to their mirror images as energetically equivalent turn structures. In order to estimate the influence of correlation energy and basis set, all turn conformers obtained at the HF/6-31G* level were reoptimized at the DFT//B3LYP/6-311+G* level of ab initio MO theory to confirm the turn structures and their energy order at a higher level of theory.

The turn structures obtained for model compound $\mathbf{1}$ were also the starting point for the study of side chain influence. For this purpose, L-alanine residues were substituted for the glycine residues followed by complete geometry optimization. Since the mirror image structures are 
not longer equivalent, they have to be additionally optimized at the same approximation levels as given for the glycine turns. To estimate the influence of a polar solvent, the resulting alanine $\alpha$-turns were also subject to complete geometry optimization in an aqueous environment employing a conductor-like polarizable continuum model (keyword: $s c r f=c p c m$; dielectric constant $\left.\varepsilon=78.4, \mathrm{CPCM} / \mathrm{HF} / 6-31 \mathrm{G}^{*}[30-32]\right)$.

\section{Results and discussion}

\section{Glycine $\alpha$-turns (Gat)}

The geometry optimization of the 1209 candidate structures from the conformational search at the $\mathrm{HF} / 6-31 \mathrm{G}^{*}$ level provided 33 stationary points on the potential hypersurface for model compound 1. One of these structures proved to be a transition state, the other 32 were conformers according to the calculated vibration frequencies. Only three conformers strictly fulfill the criterion of $1.8-2.5 \AA$ for the $\mathrm{CO} \cdots \mathrm{HN}$ distance of the $\alpha$-turn hydrogen bond. Another two conformers show a bit longer distances of about $2.7 \AA$. Thus, the five structures Gat1-Gat5 and their mirror images could be considered as hydrogen-bonded $\alpha$-turns. They are visualized in Fig. 1. The energy and free enthalpy differences between the various $\alpha$-turns and their backbone torsion angles are listed in Tables 1 and 2. The most stable structures Gat1 and Gat 2 show additional hydrogen bonds which are independent of the $\mathrm{i} \leftarrow(\mathrm{i}+4) \alpha$-turn hydrogen bond. They correspond to the classic and inverse $\gamma$ - and $\gamma^{\prime}$-turns, respectively (Tables 2 and 3). Additional hydrogen bonds corresponding to $\gamma$-turns also occur in Gat4 and Gat5. In contrast to Gat1 and Gat2, they are bifurcated with the $\alpha$-turn hydrogen bond. Turn structure Gat-3 shows a weak hydrogen bond corresponding to a hydrogen-bonded $\mathrm{C}_{5}$ pseudocycle. The hydrogen bond geometries and types of the five turns are given in Table 3. Obviously, the stability order of the $\alpha$-turns is determined by the type of the additional hydrogen bond. The competition of two hydrogen bonds to realize optimum geometries leads to deviations from ideal values, which are larger for the $\alpha$-turn hydrogen bond than for the additional one (Table 3). This situation makes the search for isolated $\alpha$-turns in protein structures difficult, since the search algorithms do not always adequately account for this problem. 
$<$ Tables 1 and 2>

$<$ Table 3>

The calculations at the higher B3LYP/6-311+G* level of ab initio MO theory and the free enthalpy data essentially confirm the results obtained at the HF/6-31G* level. The most stable $\alpha$-turns Gat1 and Gat2 are energetically equivalent now (Tables 1 and 2).

There are 10 structures among the 32 conformers of the conformational analysis without an $\alpha$-turn hydrogen bond which can be considered as $\alpha$-turns on the basis of the criterion for the distance between the $\mathrm{C}_{\alpha}$ atoms of the amino acids $\mathrm{i}$ and (i+4) introduced above. The energy and geometry data and the hydrogen bonding patterns for these turns, which are denoted by an additional " $\mathrm{d}$ " in parentheses to the turn symbol, are given in the supplementary material (Tables S1 and S2). Turns of this type can be more stable than $\alpha$-turns with an $\mathrm{i} \leftarrow(\mathrm{i}+4)$ hydrogen bond due to the formation of alternative hydrogen bonding patterns. There is no "ideal" $\alpha$-turn fulfilling the hydrogen bond criterion and having the typical backbone torsion angle values of $\varphi=-57^{\circ}$ and $\psi=-47^{\circ}$ for an $\alpha$-helix $[1,33]$ in the three central amino acids. This problem will be discussed in a later paragraph.

Obviously, the number of quantum chemically found hydrogen-bonded $\alpha$-turns is much smaller than that arising from molecular mechanics [26, 27]. It is not unusual that empirical force fields find more minimum conformations than quantum chemical methods. Therefore, it was interesting to see which quantum chemical energy minima were reached from the 23 hydrogen-bonded $\alpha$-turn minima resulting from molecular mechanics in geometry optimizations at the HF/6-31G* level. The data show that 14 of the 23 turns change into the quantum chemical $\alpha$-turns Gat1, Gat2, Gat4, and Gat5, respectively (g2, g3, g5-9, g12-14, g16, g17, g22, g23 according to the nomenclature in Ref. [27]). Another seven structures (g1, g4, g10, g15, g18-20) correspond to quantum chemically predicted $\alpha$-turns without an $\mathrm{i} \leftarrow(\mathrm{i}+4)$ hydrogen bond (Table S1 of the supplementary material), but fulfill the $\alpha$-turn distance criterion. Finally, another two structures (g11, g21) will gain importance in the discussion on the possibility of "ideal" $\alpha$-turns in a separate paragraph. Interestingly, turns grouped into the same family on the basis of molecular mechanics split into different quantum chemical minimum conformations. 


\section{Alanine $\alpha$-turns (Aat)}

In order to consider the effect of amino acid side chains, all 33 stationary points obtained for the glycine $\alpha$-turn model 1 were transformed into the corresponding L-alanine derivatives. Because of chirality, 66 structures were subject to geometry optimization to obtain also the pseudo mirror images for each structure, which are denoted by a prime added to the turn symbol. Fifty-three conformers resulted from the optimizations since some of the 66 starting structures changed into the same minimum. This aspect concerns also hydrogen-bonded $\alpha$-turns. Thus, the turn Aat4 and its mirror Aat4' and the mirror image Aat3'can no longer be localized as minimum conformations. There are no additional hydrogen-bonded $\alpha$-turns. Consequently, seven hydrogen-bonded $\alpha$-turns were obtained for an alanyl backbone, showing the same hydrogen bond patterns as the corresponding glycine turns in Table 3 . Their stabilities and backbone torsion angles are given in Tables 4 and 5. There is a fair agreement between the stability orders at the various approximation levels. Fig. 2 shows all hydrogen-bonded alanine $\alpha$-turns. Twenty of the other conformers fulfill the distance criterion for $\alpha$-turns without an $i \leftarrow(i+4)$ hydrogen bond. Their stability order, hydrogen bonding patterns and backbone torsion angles are given in Tables S3 and S4 in the supplementary material.

$<$ Tables 4 and 5>

To estimate the influence of a polar solvent on the stability and geometry of the turns, the optimizations of the alanine turns were repeated employing a conductor-like polarizable continuum model. The results for energies and backbone torsion angles are given in Table 6 .

There are no excessive changes of the vacuum data with exception of turn Aat3, which gains considerable stability, but opens its hydrogen bond. The CO$\cdots \mathrm{HN}$ distance increases from 2.37 to $3.23 \AA$.

$<$ Table 6>

\section{The "ideal" $\alpha$-turn}

The calculated hydrogen-bonded $\alpha$-turns should be compared with data from statistical analyses of the Protein Data Bank. The most comprehensive analysis for classical hydrogen- 
bonded $\alpha$-turns was performed by Pavone et al. [23]. The results of this study were essentially reproduced by another group which extended the subject to non-hydrogen-bonded $\alpha$-turns fulfilling the criterion of 6-7 $\AA$ for the distance between the $\mathrm{C}_{\alpha}$ atoms of the amino acids $\mathrm{i}$ and (i+4) [24]. Pavone and coworkers found four possible hydrogen-bonded $\alpha$-turns and their approximate mirror images. Table 7 provides the average backbone angles for these turns. In Table 8, the frequency of their occurrence in the Protein Data Bank is given. The most stable structures Aat1 and Aat2 and their mirror images Aat1'and Aat2' from our quantum chemical study can immediately be assigned to the structures II- $\boldsymbol{\alpha}_{\mathbf{R S}}, \mathbf{I I}-\boldsymbol{\alpha}_{\mathbf{L U}}, \mathbf{I I} \boldsymbol{\alpha}_{\mathbf{L S}}$, and II $\boldsymbol{\alpha}_{\mathbf{R U}}$ found by Pavone et al. (Table 7). Recently, turn Aat1' was designed in a peptide hairpin with a three-residue loop [34]. The theoretically determined turns Aat5 and Aat5' are less stable. They find no counterparts in the data set of Pavone et al. This raises the question of the theoretical counterparts for the two other $\alpha$-turn types $\mathbf{I}-\boldsymbol{\alpha}_{\mathbf{R S}}$ and $\mathbf{I}-\boldsymbol{\alpha}_{\mathbf{R U}}$ and their pseudo mirror images resulting from the data bank analysis, in particular the most frequently occurring $\mathbf{I}-\alpha_{\mathbf{R S}}$ turn.

$<$ Tables 7 and $8>$

It was already mentioned that the $\mathrm{i} \leftarrow(\mathrm{i}+4)$ hydrogen bond interaction corresponds to that in the $\alpha$-helix. An ideal isolated $\alpha$-helix turn with three central amino acids showing the typical backbone angle values of an $\alpha$-helix was neither found in our systematic conformational search nor in the data bank analysis of Pavone et al. (Table 7). This is not surprising, since the formation of $\alpha$-helices requires a critical sequence length. In shorter sequences, the formation of 310 -helices with an $i \leftarrow(i+3)$ hydrogen bond interaction is favored [1,33]. Therefore, we selected the "ideal" $\alpha$-helix turn conformation as starting point of geometry optimization. The backbone torsion angle values of the minimum conformation obtained at the HF/6-31G* level for the alanine backbone are $\varphi_{i+1}=-69.2^{\circ}, \psi_{i+1}=-23.7^{\circ} ; \varphi_{i+2}=-69.2^{\circ}, \psi_{i+2}=-12.9^{\circ}$; $\varphi_{i+3}=-95.2^{\circ}, \psi_{i+3}=2.8^{\circ}$. These angles fairly agree with those determined by Pavone et al. for the $\mathbf{I}-\boldsymbol{\alpha}_{\mathbf{R S}}$ turn. Therefore, we assigned this structure to $\mathbf{I}-\boldsymbol{\alpha}_{\mathbf{R S}}$ with the notation Aat6 in Table 7.

A detailed inspection of this structure shows correspondence with a double $\beta$-turn structure with $i \leftarrow(i+3)$ and $(i+1) \leftarrow(i+4)$ hydrogen bonding interactions (Fig. 3). Despite the close agreement of the backbone torsion angles of $\mathbf{I}-\boldsymbol{\alpha}_{\mathbf{R S}}$ and Aat6, the $\alpha$-turn hydrogen bond is not adequately realized in Aat6 and the distance between the $\mathrm{C}_{\alpha}$ atoms of the amino acids $\mathrm{i}$ and 
(i+4) is with $7.6 \AA$ a bit above the upper limit of the distance criterion. The tendency to favor the formation of hydrogen bonds with smaller pseudocycles was already observed in the other $\alpha$-turn structures for the additional hydrogen bond, which is generally better realized than the $\mathrm{i} \leftarrow(\mathrm{i}+4)$ hydrogen bond. In Aat6, this tendency is even strengthened due to the possibility of the formation of two $\beta$-turns. It could well be possible that additional factors in longer peptide and protein sequences, as for instance special side chain effects, may support the formation of the $\mathrm{i} \leftarrow(\mathrm{i}+4)$ hydrogen bond for an $\alpha$-helix-like backbone. However, the intrinsic stability is in favor of the double $\beta$-turn structure, which was obtained at all approximation levels both for glycine and alanine backbones. Structure Aat6 is distinctly more stable than the other turn structures (Table 8). This finding correlates with the highest frequency of occurrence of this turn type in the Protein Data Bank (Table 8).

A similar situation exists for the theoretical counterparts of the $\alpha$-turns $\mathbf{I}-\boldsymbol{\alpha}_{\mathbf{R U}}$ and $\mathbf{I}-\boldsymbol{\alpha}_{\mathbf{L U}}$. The backbone torsion angles of these structures agree satisfactorily with those of two other theoretically predicted double $\beta$-turn structures $\mathbf{A a t}(\mathbf{d}) \mathbf{5}$ and its pseudo mirror image $\mathbf{A a t}(\mathbf{d}) \mathbf{5}^{\prime}$ (Table 7 and Table S2 in the supplementary material). Both structures are relatively stable and clearly fulfill the $\alpha$-turn distance criterion. The turn Aat(d)5 is visualized in Fig. 4. Thus, the average backbone angle values for the four basic $\alpha$-turn types and their mirror images derived by Pavone et al. from the data bank analysis correspond to two distinct types of theoretically predicted $\alpha$-turns. The turns II- $\boldsymbol{\alpha}_{\mathbf{R S}}$ and II- $\boldsymbol{\alpha}_{\mathbf{L U}}$ and their pseudo mirror II- $\boldsymbol{\alpha}_{\mathbf{L S}}$ and II- $\boldsymbol{\alpha}_{\mathbf{R U}}$ images correspond to the theoretically predicted $\alpha$-turns Aat1/Aat1' and Aat2/Aat2' with an $\mathrm{i} \leftarrow(\mathrm{i}+4)$ hydrogen bond. The other two turn types $\mathbf{I}-\boldsymbol{\alpha}_{\mathbf{R S}}$ and $\mathbf{I}-\boldsymbol{\alpha}_{\mathbf{L U}}$ and their pseudo mirror images find their theoretical equivalents in structures with a strong tendency to double $\beta$-turn structures (Aat6/Aat6', Aat(d)5/Aat(d)5').

The theoretically estimated free enthalpy data of the turns in Table 8 show an acceptable correlation with the frequency of their occurrence in the proteins of the Protein Data Bank.

\section{Conclusions}

Our systematic conformational analysis employing quantum chemical methods at various approximation levels provides several possibilities for $\alpha$-turns as a possibility to reverse the direction of a peptide sequence via five amino acids. Only few structures realize a hydrogen 
bond between the amino acids $\mathrm{i}$ and $(\mathrm{i}+4)$ satisfactorily. More stable are structures with a strong tendency to double $\beta$-turn structures without this hydrogen bond, but with a distance smaller than 6-7 $\AA$ between the $\mathrm{C}_{\alpha}$ atoms of the amino acids i and (i+4). None of the predicted turns agrees with the ideal backbone angles of an $\alpha$-helix. There is a fair correlation of the theoretical data with the results of statistical analyses on the basis of the Protein Data Bank.

\section{Acknowledgments}

Support of this work by Deutsche Forschungsgemeinschaft (project HO 2346/1-3 and SFB 610) is gratefully acknowledged.

\section{Electronic supplementary material available}




\section{References}

1. Sewald N, Jakubke HD (2009) Peptides: Chemistry and Biology. Wiley-VCH

2. Lewis PN, Momany FA, Scheraga HA (1973) Biochem Biophys Acta 303:211-229

3. Richardson JS (1981) Adv Protein Chem 34:167-339

4. Rose GD, Gierasch LM, Smith JA (1985) Adv Protein Chem 37:1-109

5. Leszczynski JF, Rose GD (1986) Science 234:849-855

6. Thornton JM, Sibanda BL, Edwards MS, Barlow DJ (1988) Bioessays 8:63-69

7. Tramontano A, Chothia C, Lesk AM (1989) Proteins 6:382-394

8. Ring CS, Kneller DG, Langridge R, Cohen FE (1992) J Mol Biol 224:685-699

9. Kwasigroch JM, Chomilier J, Mornon JP (1996) J Mol Biol 259:855-872

10. Toniolo C (1980) CRC Crit Rev Biochem 9:1-44

11. Venkatachalam CM (1968) Biopolymers 6:1425-1436

12. Matthews BW (1972) Macromolecules 5:818-819

13. Chou PY, Fasman GD (1977) J Mol Biol 115:135-175

14. Nemethy G, Scheraga HA (1980) Biochem Biophys Res Commun 95:320-327

15. Wilmot CM, Thornton JM (1988) J Mol Biol 203:221-232

16. Milner-White EJ, Ross BM, Belhadj-Mostefa K, Poet R (1988) J Mol Biol 204:777-782

17. Hutchinson EG, Thornton JM (1994) Protein Sci 3:2207-2216

18. Perczel A, McAllister MA, Csaszar P, Csizmadia IG (1993) J Am Chem Soc 115:48494858

19. Böhm HJ (1993) J Am Chem Soc 115:6152-6158

20. Möhle K, Gußmann M, Hofmann HJ (1997) J Comput Chem 18:1415-1430

21. Möhle K, Hofmann HJ, Thiel W (2001) J Comput Chem 22:509-520

22. Möhle K, Gußmann M, Rost A, Cimiraglia R, Hofmann HJ (1997) J Phys Chem A $101: 8571-8574$

23. Pavone V, Gaeta G, Lombardi A, Nastri F, Maglio O, Isernia C, Saviano M (1996) Biopolymers 38:705-721

24. Dasgupta B, Pal L, Basu G, Chakrabarti P (2004) Proteins 55:305-315

25. Ramachandran GN, Sasisekharan V (1968) Adv Protein Chem 23:283-437

26. Nataraj DV, Srinivasan R, Sawdhamini R, Ramakrishnan C (1995) Curr Sci 69:434-447

27. Ramakrishnan C, Nataraj DV (1998) J Peptide Sci 4:239-252

28. Brooks BR, Bruccoleri RE, Olafson BD, States DJ, Swaminathan S, Karplus M (1983) J Comput Chem 4:187-217 
29. Frisch MJ, Trucks GW, Schlegel HB, Scuseria GE, Robb MA, Cheeseman JR, Montgomery JA, Vreven T, Kudin KN, Burant JC, Millam JM, Iyengar SS, Tomasi J, Barone V, Mennucci B, Cossi M, Scalmani G, Rega N, Petersson GA, Nakatsuji H, Hada M, Ehara M, Toyota K, Fukuda R, Hasegawa J, Ishida M, Nakajima T, Honda Y, Kitao O, Nakai H, Klene M, Li X, Knox JE, Hratchian HP, Cross JB, Adamo C, Jaramillo J, Gomperts R, Stratmann RE, Yazyev O, Austin AJ, Cammi R, Pomelli C, Ochterski JW, Ayala PY, Morokuma K, Voth GA, Salvador P, Dannenberg JJ, Zakrzewski VG, Dapprich S, Daniels AD, Strain MC, Farkas O, Malick DK, Rabuck AD, Raghavachari K, Foresman JB, Ortiz JV, Cui Q, Baboul AG, Clifford S, Cioslowski J, Stefanov BB, Liu G, Liashenko A, Piskorz P, Komaromi I, Martin RL, Fox DJ, Keith T, Al-Laham MA, Peng CY, Nanayakkara A, Challacombe M, Gill PMW, Johnson B, Chen W, Wong MW, Gonzalez C, Pople JA. (2004) Gaussian 03, Revision C.02. Gaussian Inc, Wallingford CT

30. Barone V, Cossi M (1998) J Phys Chem A 102:1995-2001

31. Barone V, Cossi M, Tomasi J (1998) J Comput Chem 19:404-417

32. Cossi M, Rega N, Scalmani G, Barone V (2003) J Comput Chem 24:669-681

33. Crisma M, Formaggio F, Moretto A, Toniolo C (2006) Biopolymers 84:3-12

34. Rai R, Raghothama S, Balaram P (2006) J Am Chem Soc 128:2675-2681 


\section{Tables}

Table 1 Relative energies $\Delta \mathrm{E}$ (in $\mathrm{kJ} \mathrm{mol}^{-1}$ ) and free enthalpies $\Delta \mathrm{G}$ (in $\mathrm{kJ} \mathrm{mol}^{-1}$ ) for hydrogen-bonded $\alpha$-turns of model compound 1 with glycine backbone at the HF/6-31G* and B3LYP/6-311+G* levels of ab initio MO theory

\begin{tabular}{|c|c|c|c|}
\hline \multirow[t]{2}{*}{$\alpha$-turn } & \multicolumn{2}{|c|}{$\mathrm{HF} / 6-31 \mathrm{G}^{*}$} & \multirow{2}{*}{$\begin{array}{c}\mathrm{B} 3 \mathrm{LYP} / 6-311+\mathrm{G}^{*} \\
\Delta \mathrm{E}\end{array}$} \\
\hline & $\Delta \mathrm{E}$ & $\Delta \mathrm{G}$ & \\
\hline Gat1 & $\mathbf{0 . 0}^{\mathrm{a}}$ & $\mathbf{0 . 0}^{\mathrm{b}}$ & 0.2 \\
\hline Gat2 & 2.2 & 2.7 & $0.0^{c}$ \\
\hline Gat3 & 5.7 & 9.9 & 6.3 \\
\hline Gat4 & 8.6 & 8.6 & 6.2 \\
\hline Gat5 & 12.8 & 6.8 & 6.2 \\
\hline
\end{tabular}


Table 2 Backbone torsion angles (in degrees) for hydrogen-bonded $\alpha$-turns of model compound 1 with glycine backbone at the HF/6-31G* (first line) and B3LYP/6-311+G* (second line) levels of $a b$ initio MO theory

\begin{tabular}{crrrrrr}
\hline$\alpha$-turn & $\varphi_{i+1}$ & $\psi_{i+1}$ & $\varphi_{i+2}$ & $\psi_{i+2}$ & $\varphi_{i+3}$ & $\psi_{i+3}$ \\
\hline Gat1 & -65.7 & 146.2 & 85.5 & -61.9 & -118.4 & 7.0 \\
& -65.7 & 142.7 & 83.1 & -60.8 & -108.5 & 1.7 \\
Gat2 & -75.4 & -20.8 & -85.3 & 62.4 & 119.0 & -12.1 \\
& -76.2 & -17.6 & -82.6 & 62.7 & 117.7 & -13.4 \\
Gat3 & -61.5 & -34.7 & -106.7 & 137.9 & 102.3 & -27.3 \\
& -67.3 & -27.2 & -107.9 & 121.0 & 111.0 & -30.6 \\
Gat4 & -84.7 & 75.7 & 123.3 & -26.5 & -125.8 & 9.2 \\
& -81.3 & 76.2 & 119.7 & -24.7 & -121.3 & 7.5 \\
Gat5 & -85.1 & 52.9 & -141.9 & 28.4 & 135.2 & -13.4 \\
& -82.1 & 70.4 & -112.4 & 10.1 & 117.5 & -15.9 \\
\hline
\end{tabular}


Table 3 Hydrogen bonding geometries and patterns (distances $\mathrm{R}$ in $\AA$, angles in degrees) in hydrogen-bonded $\alpha$-turns at the HF/6-31G* level of ab initio MO theory

\begin{tabular}{|c|c|c|c|c|c|c|}
\hline \multirow[t]{2}{*}{$\alpha$-turn } & \multicolumn{3}{|c|}{$\alpha$-turn hydrogen bond: $\mathrm{i} \leftarrow(\mathrm{i}+4)$} & \multicolumn{3}{|c|}{ Additional hydrogen bond } \\
\hline & $\mathrm{R}_{\mathrm{O} \cdots \mathrm{HN}}$ & $\angle \mathrm{O} \cdots \mathrm{NH}$ & $\mathrm{R}_{\mathrm{C} \alpha \cdots \mathrm{C} \alpha}{ }^{\mathrm{a}}$ & $\mathrm{R}_{\mathrm{O} \cdots \mathrm{HN}}$ & $\angle \mathrm{O} \cdots \mathrm{NH}$ & Type \\
\hline Gat1 & 2.42 & 33.2 & 4.40 & 2.20 & 26.4 & $(i+1) \leftarrow(i+3)=\gamma$ \\
\hline Gat2 & 2.37 & 29.2 & 5.37 & 2.23 & 26.9 & $(i+1) \leftarrow(i+3)=\gamma^{\prime}$ \\
\hline Gat3 & 2.24 & 21.1 & 4.77 & 2.37 & 57.7 & $(\mathrm{i}+2) \leftarrow(\mathrm{i}+2)=\mathrm{C}_{5}$ \\
\hline Gat4 & 2.71 & 35.3 & 4.07 & 2.20 & 31.6 & $\mathrm{i} \leftarrow(\mathrm{i}+2)=\gamma^{\prime}$ \\
\hline Gat5 & 2.68 & 27.5 & 5.76 & 2.07 & 21.4 & $\mathrm{i} \leftarrow(\mathrm{i}+2)=\gamma^{\prime}$ \\
\hline
\end{tabular}

${ }^{\text {a }}$ Distance between the $\mathrm{C}_{\alpha}$-atoms of the amino acids $\mathrm{i}$ and (i+4) 
Table 4 Relative energies $\Delta \mathrm{E}$ (in $\mathrm{kJ} \mathrm{mol}^{-1}$ ) and free enthalpies $\Delta \mathrm{G}$ (in $\mathrm{kJ} \mathrm{mol}^{-1}$ ) for hydrogen-bonded $\alpha$-turns of model compound 1 with alanine backbone at the HF/6-31G* and B3LYP/6-311+G* levels of ab initio MO theory

\begin{tabular}{|c|c|c|c|}
\hline \multirow[t]{2}{*}{$\alpha$-turn } & \multicolumn{2}{|c|}{$\mathrm{HF} / 6-31 \mathrm{G}^{*}$} & \multirow{2}{*}{$\begin{array}{c}\text { B3LYP/6-311+G* } \\
\Delta \mathrm{E}\end{array}$} \\
\hline & $\Delta \mathrm{E}$ & $\Delta \mathrm{G}$ & \\
\hline Aat1 & $0.0^{\mathrm{a}}$ & $\mathbf{0 . 0}^{\mathrm{b}}$ & $0.0^{\mathrm{c}}$ \\
\hline Aat2 & 1.1 & 3.2 & 2.0 \\
\hline Aat3 & 5.3 & 8.1 & 7.5 \\
\hline Aat2' & 9.5 & 8.2 & 8.2 \\
\hline Aat1' & 10.4 & 13.2 & 11.0 \\
\hline Aat5 & 13.5 & 11.3 & 12.4 \\
\hline Aat5' & 15.9 & 15.2 & 13.1 \\
\hline
\end{tabular}


Table 5 Backbone torsion angles (in degrees) for hydrogen-bonded $\alpha$-turns of model compound 1 with alanine backbone at the HF/6-31G* (first line) and B3LYP/6-311+G* (second line) levels of $a b$ initio MO theory

\begin{tabular}{crrrrrr}
\hline a-turn & $\varphi_{i+1}$ & $\psi_{i+1}$ & $\varphi_{i+2}$ & $\psi_{i+2}$ & $\varphi_{i+3}$ & $\psi_{i+3}$ \\
\hline Aat1 & -63.9 & 133.4 & 75.1 & -51.7 & -102.4 & -4.1 \\
& -63.7 & 133.1 & 74.1 & -49.7 & -100.4 & -5.2 \\
Aat2 & -74.2 & -22.7 & -85.5 & 68.5 & 64.5 & 34.5 \\
& -76.2 & -18.2 & -82.4 & 68.3 & 69.5 & 26.5 \\
Aat3 & -63.2 & -31.6 & -111.4 & 136.8 & 73.9 & 9.5 \\
& -68.3 & -24.3 & -111.4 & 129.5 & 82.0 & -7.3 \\
Aat2' & 63.4 & 34.8 & 74.6 & -53.0 & -115.4 & 4.6 \\
& 63.7 & 32.3 & 72.7 & -52.7 & -115.9 & 6.8 \\
Aat1 & 54.8 & -138.5 & -85.9 & 71.1 & 63.6 & 36.6 \\
& 56.2 & -135.9 & -83.6 & 69.3 & 65.4 & 33.0 \\
Aat5 $^{*}$ & -88.6 & 49.2 & -145.8 & 18.8 & -171.9 & -33.8 \\
& -85.2 & 49.6 & -142.4 & 17.2 & -175.4 & -34.9 \\
Aat5 & 75.0 & -64.4 & -158.9 & -44.5 & -145.4 & 21.3 \\
& 72.8 & -63.0 & -157.4 & -49.6 & -136.5 & 16.9 \\
\hline
\end{tabular}


Table 6 Relative energies (in $\mathrm{kJ} \mathrm{mol}^{-1}$ ) and backbone torsion angles (in degrees) for hydrogen-bonded $\alpha$-turns of model compound $\mathbf{1}$ with alanine backbone after geometry optimization at the CPCM/HF/6-31G* level of ab initio MO theory

\begin{tabular}{|c|c|c|c|c|c|c|c|}
\hline \multirow[t]{2}{*}{$\alpha$-turn } & \multirow{2}{*}{$\begin{array}{c}\mathrm{CPCM} / \mathrm{HF} / 6-31 \mathrm{G}^{*}{ }^{\mathrm{a}} \\
\Delta \mathrm{E}\end{array}$} & \multicolumn{6}{|c|}{ Backbone torsion angles } \\
\hline & & $\varphi_{i+1}$ & $\psi_{i+1}$ & $\varphi_{i+2}$ & $\psi_{\mathrm{i}+2}$ & $\varphi_{\mathrm{i}+3}$ & $\psi_{\mathrm{i}+3}$ \\
\hline Aat1 & 6.8 & -63.0 & 138.8 & 74.8 & -52.0 & -94.1 & -17.3 \\
\hline Aat2 & 2.9 & -70.1 & -33.6 & -90.8 & 76.7 & 60.3 & 40.1 \\
\hline Aat3 & $0.0^{b}$ & -70.5 & -34.3 & -117.8 & 119.4 & 58.9 & 41.0 \\
\hline Aat2' & 11.7 & 57.5 & 42.4 & 76.3 & -47.7 & -101.4 & -9.5 \\
\hline Aat1' & 20.3 & 56.3 & -129.4 & -90.6 & 77.5 & 60.8 & 39.5 \\
\hline Aat5 & 37.9 & -90.5 & 50.3 & -143.6 & 23.0 & -175.3 & -36.7 \\
\hline Aat5' & 21.1 & 74.7 & -59.1 & -150.6 & -50.5 & -136.4 & 10.8 \\
\hline
\end{tabular}


Table 7 Comparison of the backbone torsion angles (in degrees) of the corresponding hydrogen-bonded $\alpha$-turns from Protein Data Bank analysis ${ }^{\mathrm{a}}$ and from theory at the HF/6$31 \mathrm{G}^{*}$ level

\begin{tabular}{|c|c|c|c|c|c|c|}
\hline$\alpha$-turn & $\varphi_{i+1}$ & $\psi_{\mathrm{i}+1}$ & $\varphi_{i+2}$ & $\psi_{i+2}$ & $\varphi_{i+3}$ & $\psi_{\mathrm{i}+3}$ \\
\hline$I-\alpha_{R S}$ & $-60 \pm 11$ & $-29 \pm 13$ & $-72 \pm 14$ & $-29 \pm 15$ & $-96 \pm 20$ & $-20 \pm 17$ \\
\hline Aat6 & -69.2 & -23.7 & -69.2 & -12.9 & -95.2 & 2.8 \\
\hline$I-\alpha_{L S}$ & $48 \pm 22$ & $42 \pm 14$ & $67 \pm 9$ & $33 \pm 14$ & $70 \pm 11$ & $32 \pm 12$ \\
\hline Aat6 $^{\prime}$ & 61.9 & 32.1 & 58.4 & 26.5 & 63.3 & 25.9 \\
\hline II- $\alpha_{R S}$ & $-59 \pm 10$ & $129 \pm 15$ & $88 \pm 15$ & $-16 \pm 19$ & $-91 \pm 22$ & $-32 \pm 18$ \\
\hline Aat1 & -63.9 & 133.4 & 75.1 & -51.7 & -102.4 & -4.1 \\
\hline$I I-\alpha_{L S}$ & $53 \pm 15$ & $137 \pm 25$ & $-95 \pm 12$ & $81 \pm 23$ & $57 \pm 5$ & $38 \pm 8$ \\
\hline Aat1' $^{\prime}$ & 54.8 & -138.5 & -85.9 & 71.1 & 63.6 & 36.6 \\
\hline $\mathbf{I}-\alpha_{L U}$ & $-61 \pm 12$ & $158 \pm 15$ & $64 \pm 17$ & $37 \pm 21$ & $62 \pm 12$ & $38 \pm 8$ \\
\hline $\operatorname{Aat}(d) 5$ & -60.6 & 129.2 & 56.7 & 29.9 & 65.7 & 22.9 \\
\hline$I-\alpha_{R U}$ & $59 \pm 18$ & $-157 \pm 31$ & $-67 \pm 17$ & $-29 \pm 20$ & $-68 \pm 12$ & $-39 \pm 12$ \\
\hline $\operatorname{Aat}(d) 5^{\prime}$ & 55.6 & -125.9 & -67.7 & -15.3 & -94.4 & 2.8 \\
\hline II- $\alpha_{L U}$ & $-65 \pm 15$ & $-20 \pm 15$ & $-90 \pm 17$ & $16 \pm 44$ & $86 \pm 18$ & $37 \pm 27$ \\
\hline Aat2 & -74.2 & -22.7 & -85.5 & 68.5 & 64.5 & 34.5 \\
\hline II- $\alpha_{R U}$ & $54 \pm 8$ & $39 \pm 15$ & $67 \pm 13$ & $-5 \pm 31$ & $-125 \pm 11$ & $-34 \pm 32$ \\
\hline Aat2' & 63.4 & 34.8 & 74.6 & -53.0 & -115.4 & 4.6 \\
\hline
\end{tabular}


Table 8 Comparison of the occurrence of hydrogen-bonded $\alpha$-turns in the Protein Data Bank (PDB) with the relative free enthalpies $\Delta \mathrm{G}$ (in $\mathrm{kJ} \mathrm{mol}^{-1}$ ) of $\alpha$-turns theoretically predicted at the $\mathrm{HF} / 6-31 \mathrm{G}^{*}$ level of ab initio MO theory

\begin{tabular}{|c|c|c|c|}
\hline \multicolumn{2}{|c|}{$\alpha$-turns (PDB) ${ }^{\mathrm{a}}$} & \multicolumn{2}{|c|}{$\alpha$-turns (theory) } \\
\hline Type & Number & Type & $\Delta \mathrm{G}$ \\
\hline $\mathbf{I}-\alpha_{R S}$ & 238 & Aat6 & -9.3 \\
\hline II- $\alpha_{R S}$ & 39 & Aat1 & 0.0 \\
\hline $\mathbf{I}-\alpha_{\mathbf{R U}}$ & 28 & $\operatorname{Aat}(d) 5^{\prime}$ & 0.5 \\
\hline $\mathbf{I}-\alpha_{\mathbf{L U}}$ & 14 & $\operatorname{Aat}(d) 5$ & 6.2 \\
\hline II- $\alpha_{\mathrm{RU}}$ & 9 & Aat2' & 8.2 \\
\hline II- $\alpha_{L S}$ & 8 & Aat1' & 13.2 \\
\hline$I I-\alpha_{L U}$ & 8 & Aat2 & 3.2 \\
\hline $\mathbf{I}-\alpha_{L S}$ & 5 & Aat6' $^{\prime}$ & 16.4 \\
\hline
\end{tabular}




\section{Figure captions}

Fig. 1 Hydrogen-bonded glycine $\alpha$-turns at the HF/6-31G* level of ab initio MO theory

Fig. 2 Hydrogen-bonded alanine $\alpha$-turns at the HF/6-31G* level of ab initio MO theory

Fig. 3 Most stable double $\beta$-turn Aat6 (left: front view, right: top view)

Fig. 4 Stable double $\beta$-turn Aat(d)5 


$$
\mathrm{i} \leftarrow(\mathrm{i}+4)
$$
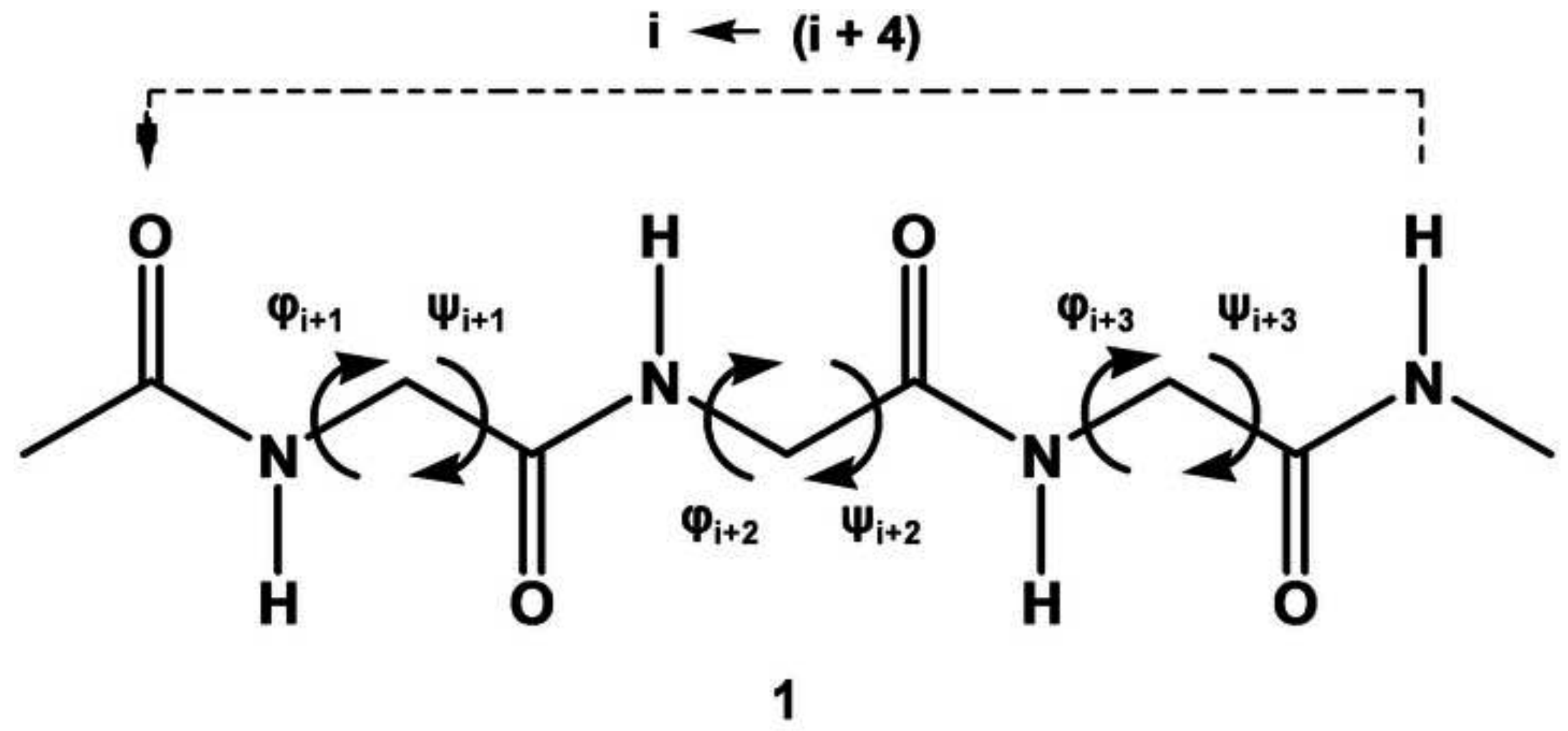
Click here to download high resolution image

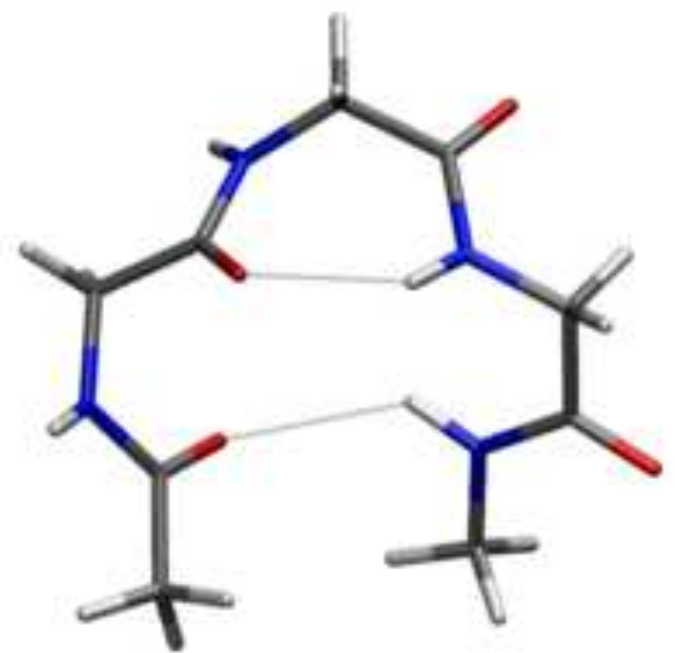

Gat1

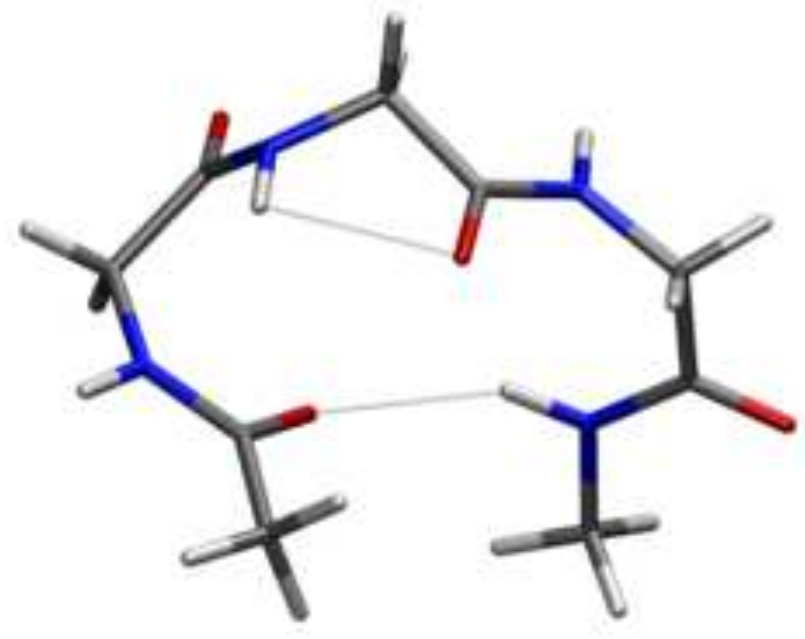

Gat3

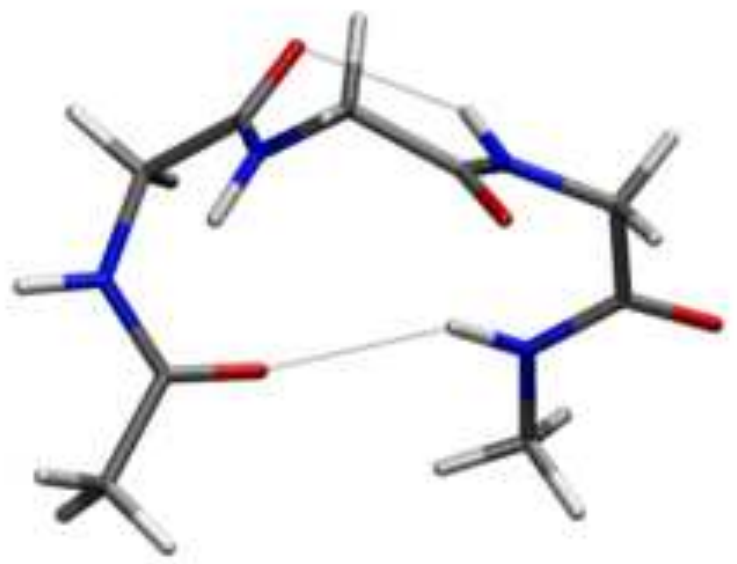

Gat2

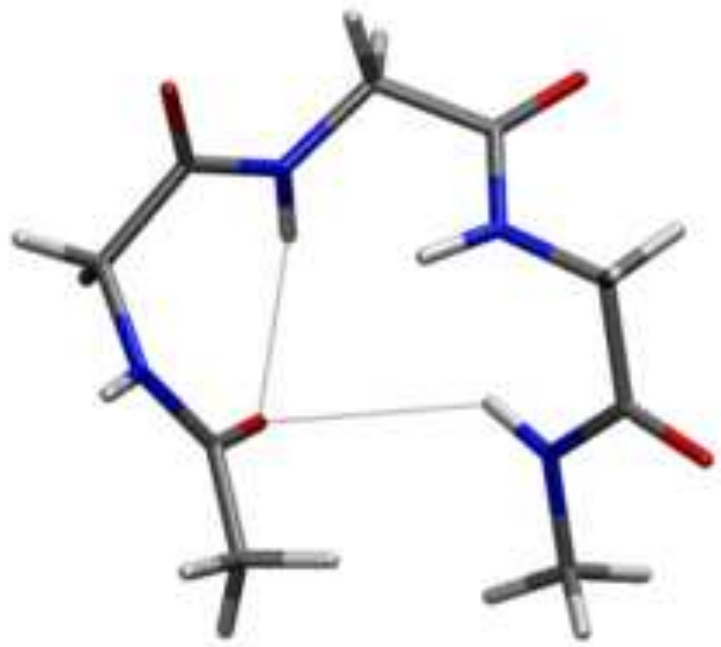

Gat4

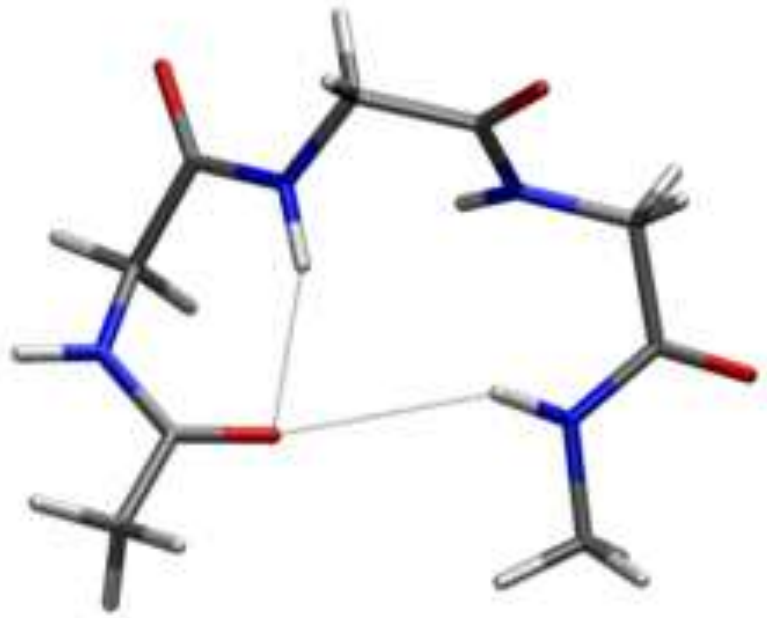

Gat5 


\section{Figure 2}

Click here to download high resolution image

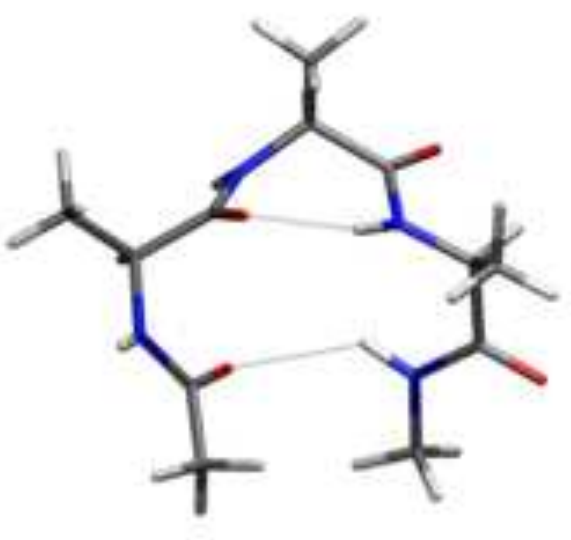

Aat1

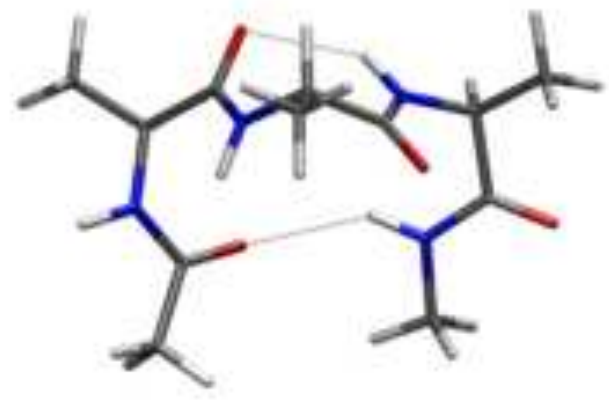

Aat2

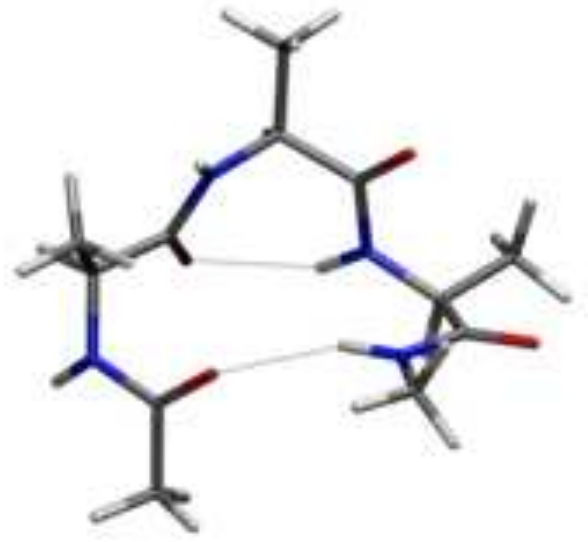

Aat1 ${ }^{*}$

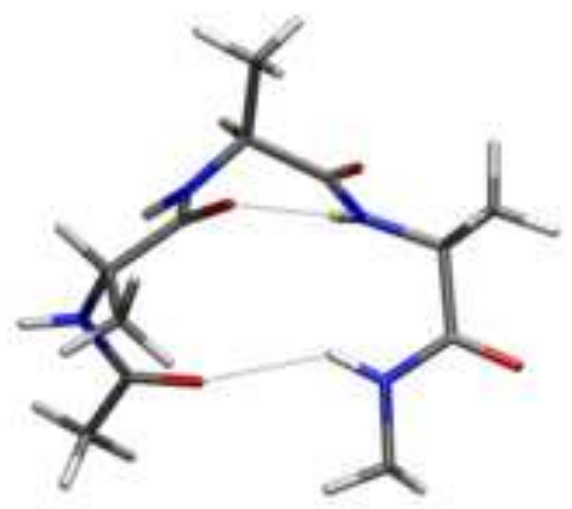

Aat2'

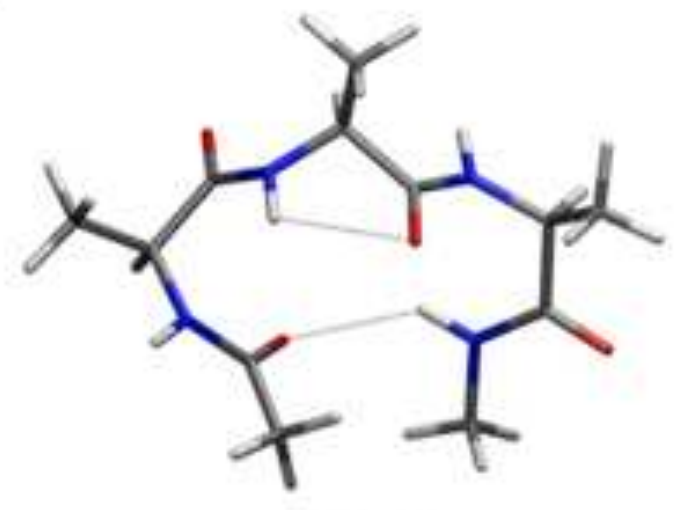

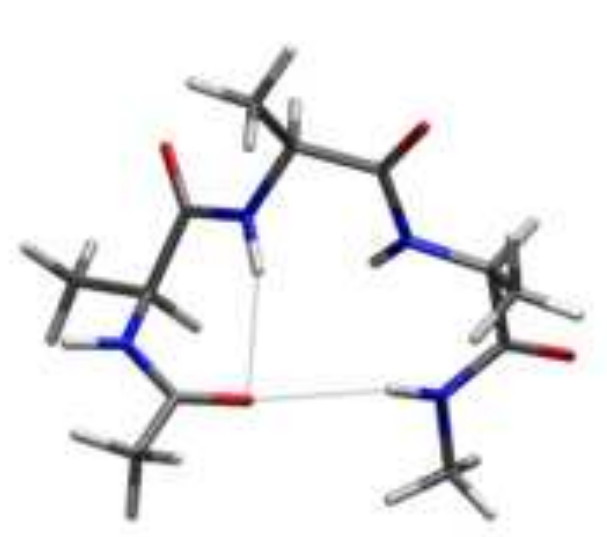

Aat5

\section{Aat3}

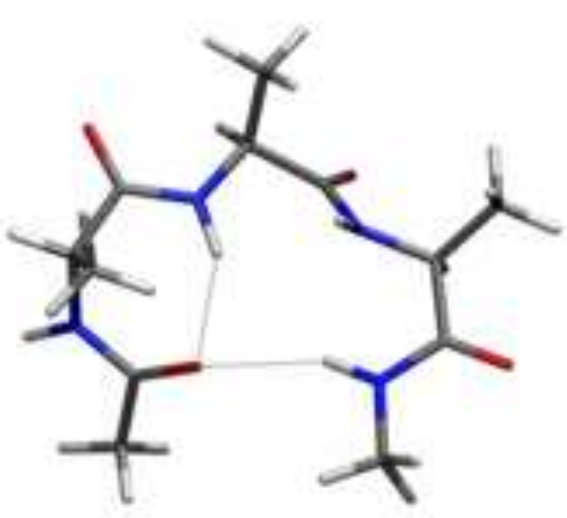

Aat5 
Click here to download high resolution image
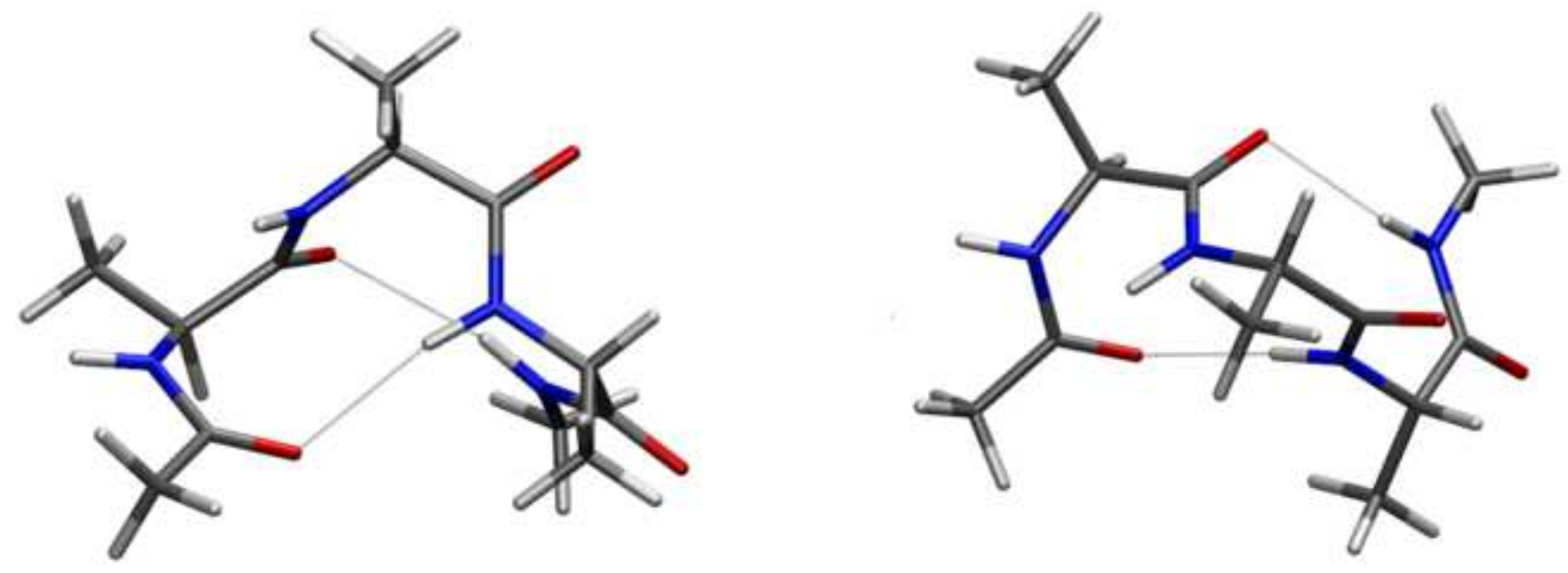

Aat6 
Click here to download high resolution image

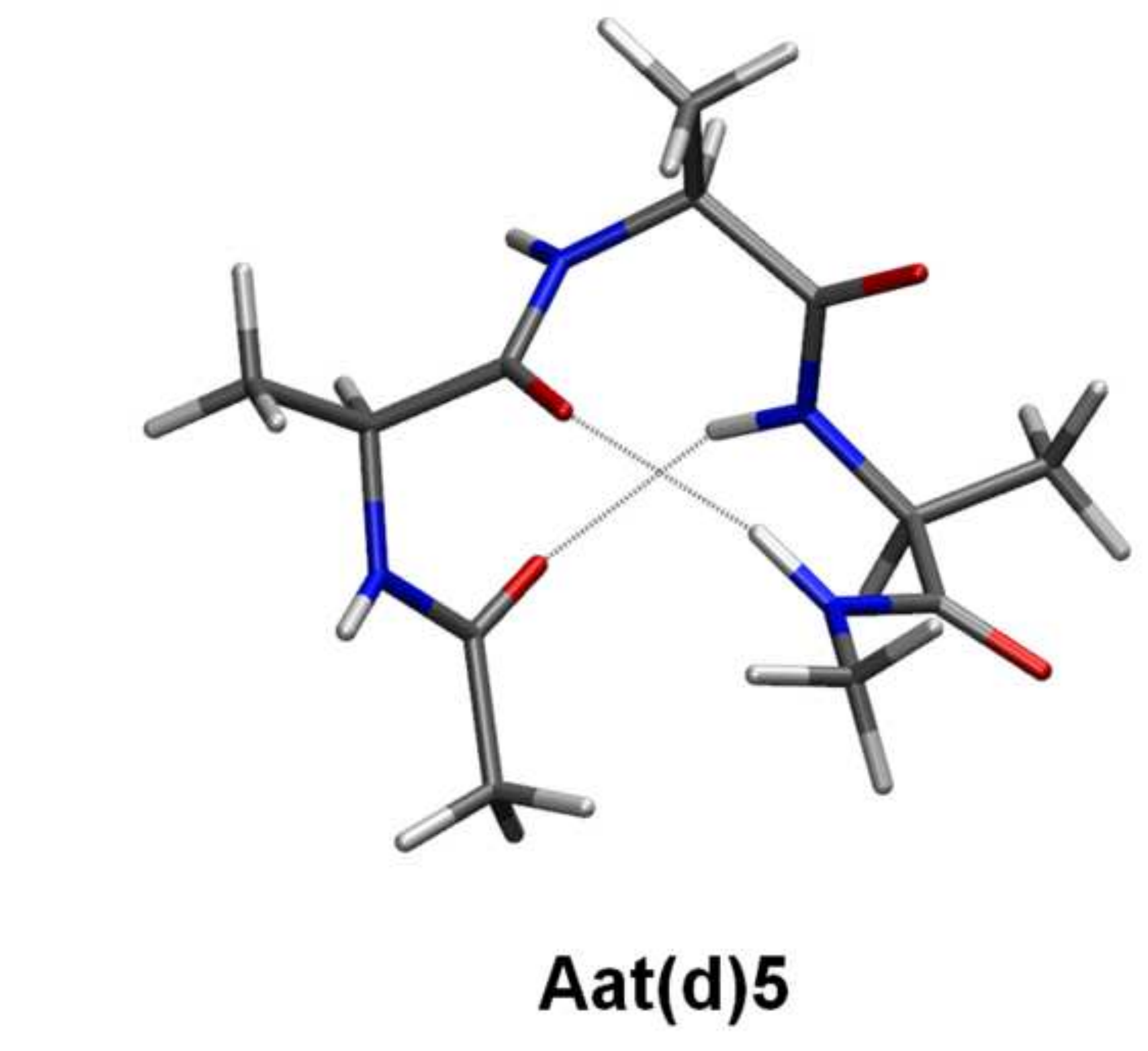

Aat(d)5

Click here to download high resolution image

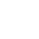
Clck here to downl

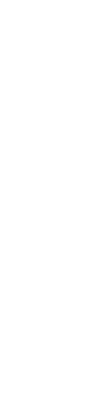

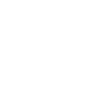

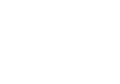

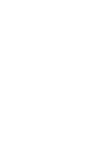

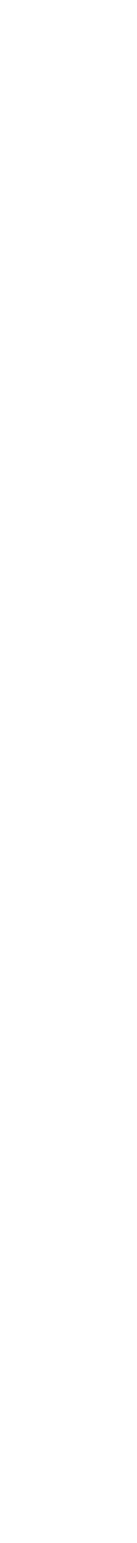




\section{Supplementary material}

\section{How many hydrogen-bonded $\alpha$-turns are possible?}

Anette Schreiber $\cdot$ Peter Schramm $\cdot$ Hans-Jörg Hofmann $(\bowtie)$

Institute of Biochemistry, Faculty of Biosciences, Pharmacy, and Psychology, University of Leipzig, D-04103 Leipzig, Germany

e-mail: hofmann@uni-leipzig.de

\section{Contents}

Energetic relationships between glycine $\alpha$-turns without $\mathrm{i} \leftarrow(\mathrm{i}+4)$ hydrogen bond $\mathrm{S} 2$

Backbone torsion angles of glycine $\alpha$-turns without $\mathrm{i} \leftarrow(\mathrm{i}+4)$ hydrogen bond S3

Energetic relationships between alanine $\alpha$-turns without $i \leftarrow(i+4)$ hydrogen bond S4

Backbone torsion angles of alanine $\alpha$-turns without $\mathrm{i} \leftarrow(\mathrm{i}+4)$ hydrogen bond 
Table S1 Relative energies $\Delta \mathrm{E}$ (in $\mathrm{kJ} / \mathrm{mol}$ ), free enthalpies $\Delta \mathrm{G}$ (in $\mathrm{kJ} / \mathrm{mol}$ ) and hydrogen bonding patterns for $\alpha$-turns of model compound 1 with glycine backbone without an $\mathrm{i} \leftarrow(\mathrm{i}+4)$ hydrogen bond, but fulfilling the distance criterion $\mathrm{R}<7 \AA$ for the distance between the $\mathrm{C}_{\alpha}$ atoms of the amino acids $\mathrm{i}$ and $(\mathrm{i}+4)$ at the HF/6-31G* level of ab initio MO theory

\begin{tabular}{|c|c|c|c|c|}
\hline \multirow[t]{2}{*}{$\alpha$-turn } & \multicolumn{4}{|c|}{$\mathrm{HF} / 6-31 \mathrm{G}^{*}$} \\
\hline & $\Delta \mathrm{E}$ & $\Delta \mathrm{G}$ & $\mathrm{R}_{\mathrm{C} \alpha \cdots \mathrm{C} \alpha}$ & Hydrogen bonds \\
\hline Gat(d)1 & $0.0^{\mathrm{a}}$ & $0.0^{b}$ & 4.69 & $\mathrm{i} \leftarrow(\mathrm{i}+2),(\mathrm{i}+1) \leftarrow(\mathrm{i}+3),(\mathrm{i}+1) \rightarrow(\mathrm{i}+3)$ \\
\hline Gat(d)2 & 2.1 & 3.5 & 5.81 & $\mathrm{i} \leftarrow(\mathrm{i}+2) /(\mathrm{i}+3),{ }^{\mathrm{c}, \mathrm{d}}(\mathrm{i}+2) \leftarrow(\mathrm{i}+4)$ \\
\hline Gat(d)3 & 3.1 & 4.0 & 4.21 & $\mathrm{i} \leftarrow(\mathrm{i}+2),(\mathrm{i}+1) \leftarrow(\mathrm{i}+3),(\mathrm{i}+2) \leftarrow(\mathrm{i}+4)$ \\
\hline Gat(d)4 & 6.2 & 4.7 & 4.50 & $\mathrm{i} \leftarrow(\mathrm{i}+3),(\mathrm{i}+1) \leftarrow(\mathrm{i}+4)$ \\
\hline Gat(d)5 & 8.9 & 6.3 & 5.49 & $\mathrm{i} \leftarrow(\mathrm{i}+3)$ \\
\hline Gat(d)6 & 10.0 & 10.8 & 6.02 & $\mathrm{i} \leftarrow(\mathrm{i}+3),(\mathrm{i}+2) \leftarrow(\mathrm{i}+4)$ \\
\hline Gat(d)7 & 14.2 & 5.8 & 6.45 & $\mathrm{i} \leftarrow(\mathrm{i}+2),(\mathrm{i}+2) \leftarrow(\mathrm{i}+4)$ \\
\hline Gat(d)8 & 16.6 & 3.3 & 6.54 & $(\mathrm{i}+1) \leftarrow(\mathrm{i}+1) /(\mathrm{i}+4)^{\mathrm{c}, \mathrm{d}}$ \\
\hline Gat(d)9 & 20.8 & 11.8 & 4.78 & $(\mathrm{i}+2) \leftarrow(\mathrm{i}+2) /(\mathrm{i}+4)^{\mathrm{c}, \mathrm{d}}$ \\
\hline Gat(d)10 & 44.5 & 37.6 & 4.36 & $(\mathrm{i}+1) \longleftarrow(\mathrm{i}+4)$ \\
\hline \multicolumn{5}{|c|}{${ }^{\mathrm{a}} \mathrm{E}_{\mathrm{T}}=-867.462001$ a.u.; for comparison: $\mathrm{E}_{\mathrm{T}}($ Gat1) $=-867.457489$ a.u. (see Table 1) } \\
\hline \multicolumn{5}{|c|}{${ }^{\mathrm{b}} \mathrm{G}_{\mathrm{T}}=-867.217159$ a.u.; for comparison: $\mathrm{G}_{\mathrm{T}}($ Gat1 $)=-867.215068$ a.u. (see Table 1$)$} \\
\hline \multicolumn{5}{|l|}{${ }^{\mathrm{c}}$ Bifurcated } \\
\hline d Weak & & & & \\
\hline
\end{tabular}


Table S2 Backbone torsion angles (in degrees) for $\alpha$-turns of model compound 1 with glycine backbone without an $\mathrm{i} \leftarrow(\mathrm{i}+4)$ hydrogen bond but fulfilling the criterion for the distance $\mathrm{R}<7 \AA$ between the $\mathrm{C}_{\alpha}$ atoms of the amino acids $\mathrm{i}$ and $(\mathrm{i}+4)$ at the HF/6-31G* level of ab initio MO theory

\begin{tabular}{lrrrrrr}
\hline$\alpha$-turn & $\varphi_{i+1}$ & $\psi_{i+1}$ & $\varphi_{i+2}$ & $\psi_{i+2}$ & $\varphi_{i+3}$ & $\psi_{i+3}$ \\
\hline Gat(d)1 & -86.7 & 65.0 & 79.1 & -76.0 & -72.6 & 156.6 \\
Gat(d)2 & -69.6 & 112.8 & 73.9 & 20.1 & 83.3 & -81.0 \\
Gat(d)3 & -81.8 & 85.5 & 84.6 & -61.6 & -77.3 & 91.1 \\
Gat(d)4 & -61.8 & 128.9 & 68.0 & 12.9 & 95.8 & -5.3 \\
Gat(d)5 & -71.5 & -19.9 & -119.0 & 37.5 & 70.7 & -162.1 \\
Gat(d)6 & -67.6 & -26.7 & -114.7 & 28.4 & 81.7 & -87.8 \\
Gat(d)7 & -81.6 & 77.5 & 72.0 & -165.4 & 87.3 & -67.1 \\
Gat(d)8 & -177.3 & 173.6 & -61.3 & 139.8 & 96.1 & -12.6 \\
Gat(d)9 & -70.9 & 158.4 & 89.4 & -139.0 & -86.8 & 55.9 \\
Gat(d)10 & -99.2 & -81.8 & -70.3 & -19.8 & -115.9 & 18.9 \\
\hline
\end{tabular}


Table S3 Relative energies $\Delta \mathrm{E}$ (in $\mathrm{kJ} / \mathrm{mol}$ ), free enthalpies $\Delta \mathrm{G}$ (in $\mathrm{kJ} / \mathrm{mol}$ ) and hydrogen bonding patterns for $\alpha$-turns of model compound 1 with alanine backbone without an $\mathrm{i} \leftarrow(\mathrm{i}+4)$ hydrogen bond, but fulfilling the distance criterion $\mathrm{R}<7 \AA$ for the distance between the $\mathrm{C}_{\alpha}$ atoms of the amino acids $\mathrm{i}$ and $(\mathrm{i}+4)$ at the HF/6-31G* level of ab initio MO theory

\begin{tabular}{|c|c|c|c|c|}
\hline \multirow[t]{2}{*}{$\alpha$-turn } & \multicolumn{4}{|c|}{$\mathrm{HF} / 6-31 \mathrm{G}^{*}$} \\
\hline & $\Delta \mathrm{E}$ & $\Delta \mathrm{G}$ & $\mathrm{R}_{\mathrm{C} \alpha \cdots \mathrm{C} \alpha}$ & Hydrogen bonds \\
\hline Aat(d)1 & $\mathbf{0 . 0}^{\mathrm{a}}$ & $\mathbf{0 . 0}{ }^{b}$ & 4.43 & $\mathrm{i} \leftarrow(\mathrm{i}+2),(\mathrm{i}+1) \leftarrow(\mathrm{i}+3),(\mathrm{i}+1) \rightarrow(\mathrm{i}+3)$ \\
\hline Aat(d)2 & 0.6 & 0.6 & 4.30 & $\mathrm{i} \leftarrow(\mathrm{i}+2),(\mathrm{i}+1) \leftarrow(\mathrm{i}+3),(\mathrm{i}+2) \leftarrow(\mathrm{i}+4)$ \\
\hline Aat(d)3 & 1.8 & 2.8 & 5.59 & $\mathrm{i} \leftarrow(\mathrm{i}+2) /(\mathrm{i}+3),{ }^{\mathrm{c}}(\mathrm{i}+2) \leftarrow(\mathrm{i}+4)$ \\
\hline Aat(d)4 & 5.6 & 4.5 & 6.97 & $\mathrm{i} \leftarrow(\mathrm{i}+2),(\mathrm{i}+1) \leftarrow(\mathrm{i}+4)$ \\
\hline $\operatorname{Aat}(d) 5^{\prime}$ & 7.1 & 6.3 & 4.47 & $\mathrm{i} \leftarrow(\mathrm{i}+3),(\mathrm{i}+1) \leftarrow(\mathrm{i}+4)$ \\
\hline Aat(d)3 & 9.1 & 11.2 & 5.71 & $\mathrm{i} \leftarrow(\mathrm{i}+3),(\mathrm{i}+2) \leftarrow(\mathrm{i}+4)$ \\
\hline Aat(d)6 & 11.3 & 9.8 & 5.64 & $\mathrm{i} \leftarrow(\mathrm{i}+3),(\mathrm{i}+2) \rightarrow(\mathrm{i}+3)$ \\
\hline Aat(d)7 & 11.8 & 11.3 & 5.93 & $\mathrm{i} \leftarrow(\mathrm{i}+3),(\mathrm{i}+2) \leftarrow(\mathrm{i}+4)$ \\
\hline $\operatorname{Aat}(d) 5$ & 12.1 & 12.0 & 4.97 & $\mathrm{i} \leftarrow(\mathrm{i}+3),(\mathrm{i}+1) \leftarrow(\mathrm{i}+4)$ \\
\hline $\operatorname{Aat}(d) 1^{\prime}$ & 13.7 & 16.3 & 4.43 & $\mathrm{i} \leftarrow(\mathrm{i}+2),(\mathrm{i}+1) \leftarrow(\mathrm{i}+3),(\mathrm{i}+1) \rightarrow(\mathrm{i}+3)^{\mathrm{d}}$ \\
\hline Aat(d)2' & 14.8 & 18.0 & 4.13 & $\mathrm{i} \leftarrow(\mathrm{i}+2),(\mathrm{i}+1) \leftarrow(\mathrm{i}+3),(\mathrm{i}+2) \leftarrow(\mathrm{i}+4)$ \\
\hline Aat(d)8 & 16.9 & 4.9 & 6.84 & $(i+1) \rightarrow(i+1),{ }^{d}(i+1) \leftarrow(i+4)$ \\
\hline Aat(d)4' & 18.0 & 16.3 & 6.35 & $\mathrm{i} \leftarrow(\mathrm{i}+2),(\mathrm{i}+1) \leftarrow(\mathrm{i}+4)$ \\
\hline $\operatorname{Aat}(d) 9^{\prime}$ & 18.6 & 11.1 & 5.06 & $\mathrm{i} \leftarrow(\mathrm{i}+2),(\mathrm{i}+1) \leftarrow(\mathrm{i}+3),(\mathrm{i}+2) \leftarrow(\mathrm{i}+4)$ \\
\hline Aat(d)9 & 19.5 & 6.4 & 4.91 & $\mathrm{i} \leftarrow(\mathrm{i}+2),(\mathrm{i}+1) \leftarrow(\mathrm{i}+3)$ \\
\hline $\operatorname{Aat}(d) 8^{\prime}$ & 20.4 & 7.1 & 5.85 & $(i+1) \rightarrow(i+1),{ }^{d}(i+1) \leftarrow(i+4)$ \\
\hline Aat(d) $7^{\prime}$ & 21.4 & 21.5 & 5.88 & $\mathrm{i} \leftarrow(\mathrm{i}+3),(\mathrm{i}+2) \leftarrow(\mathrm{i}+4)$ \\
\hline Aat(d)10 & 25.3 & 21.4 & 6.57 & $\mathrm{i} \leftarrow(\mathrm{i}+2),(\mathrm{i}+2) \leftarrow(\mathrm{i}+4)$ \\
\hline $\operatorname{Aat}(d) 11^{\prime}$ & 32.9 & 19.1 & 6.24 & $\mathrm{i} \leftarrow(\mathrm{i}+2),(\mathrm{i}+2) \rightarrow(\mathrm{i}+2),(\mathrm{i}+2) \leftarrow(\mathrm{i}+4)$ \\
\hline Aat(d)12 & 37.0 & 24.6 & 4.52 & $(\mathrm{i}+1) \longleftarrow(\mathrm{i}+4)$ \\
\hline \multicolumn{5}{|c|}{${ }^{\mathrm{a}} \mathrm{E}_{\mathrm{T}}=-984.570085$ a.u.; for comparison: $\mathrm{E}_{\mathrm{T}}($ Aat1) $=-984.565125$ a.u. (see Table 4) } \\
\hline \multicolumn{5}{|c|}{${ }^{\mathrm{b}} \mathrm{G}_{\mathrm{T}}=-984.239048$ a.u.; for comparison: $\mathrm{G}_{\mathrm{T}}($ Aat1 $)=-984.236825$ a.u. (see Table 4$)$} \\
\hline
\end{tabular}


Table S4 Backbone torsion angles (in degrees) for $\alpha$-turns of model compound $\mathbf{1}$ with alanine backbone without an $\mathrm{i} \leftarrow(\mathrm{i}+4)$ hydrogen bond but fulfilling the criterion for the distance $\mathrm{R}<7 \AA$ between the $\mathrm{C}_{\alpha}$ atoms of the amino acids $\mathrm{i}$ and $(\mathrm{i}+4)$ at the HF/6-31G* level of ab initio MO theory

\begin{tabular}{|c|c|c|c|c|c|c|}
\hline$\alpha$-turn & $\varphi_{\mathrm{i}+1}$ & $\psi_{\mathrm{i}+1}$ & $\varphi_{i+2}$ & $\psi_{i+2}$ & $\varphi_{\mathrm{i}+3}$ & $\psi_{i+3}$ \\
\hline Aat(d)1 & -88.9 & 69.3 & 69.9 & -69.1 & -64.3 & 135.6 \\
\hline Aat(d)2 & -82.8 & 86.3 & 74.7 & -54.5 & -77.9 & 93.5 \\
\hline $\operatorname{Aat}(d) 3^{\prime}$ & 60.0 & -114.1 & -67.4 & -26.4 & -84.4 & 81.8 \\
\hline Aat(d)4 & -81.4 & 78.9 & 50.3 & -136.7 & -91.2 & 6.1 \\
\hline Aat(d)5' & 55.6 & -125.9 & -67.7 & -15.3 & -94.4 & 2.8 \\
\hline Aat(d)3 & -66.1 & 117.4 & 55.7 & 36.3 & 72.2 & -72.1 \\
\hline Aat(d)6 & -70.6 & -20.7 & 127.3 & 46.0 & 53.7 & -145.2 \\
\hline Aat(d)7 & -67.7 & -25.8 & -120.9 & 33.3 & 72.7 & -77.0 \\
\hline Aat(d)5 & -60.6 & 129.2 & 56.7 & 29.9 & 65.7 & 22.9 \\
\hline $\operatorname{Aat}(d) 1^{\prime}$ & 75.6 & -60.2 & -80.8 & 77.0 & 53.9 & -132.9 \\
\hline $\operatorname{Aat}(d) 2^{\prime}$ & 72.4 & -77.1 & -87.3 & 64.6 & 66.7 & -83.4 \\
\hline Aat(d)8 & -155.8 & 152.0 & -59.9 & 135.5 & 66.9 & 19.6 \\
\hline Aat(d) $4^{\prime}$ & 72.0 & -71.0 & -55.8 & 138.9 & 65.9 & 19.9 \\
\hline $\operatorname{Aat}(d) 9^{\prime}$ & 75.1 & -60.9 & -86.2 & 70.2 & 72.7 & -61.0 \\
\hline Aat(d)9 & -87.9 & 72.6 & 76.0 & -49.3 & -100.6 & 4.2 \\
\hline Aat(d)8 & -156.8 & 157.4 & 55.7 & -133.4 & -97.6 & 9.9 \\
\hline $\operatorname{Aat}(d) 7^{\prime}$ & 59.0 & 41.7 & 97.4 & -21.0 & -83.4 & 88.1 \\
\hline Aat(d)10 & -81.9 & 79.4 & 53.9 & -142.4 & 78.8 & -50.9 \\
\hline Aat(d)11' & 77.7 & -43.2 & -151.6 & 147.6 & 76.3 & -55.3 \\
\hline Aat(d)12 & -103.9 & -70.9 & -71.7 & -18.5 & -124.5 & 22.1 \\
\hline
\end{tabular}

